\title{
Simultaneous Determination of Residues of Non-Steroidal Anti-Inflammatory Drugs and Glucocorticosteroids in Animal Muscle by Liquid Chromatography-Tandem Mass Spectrometry
}

\author{
Piotr Jedziniak $^{1}$ - Malgorzata Olejnik ${ }^{1} \cdot$ Konrad Pietruk $^{1} \cdot$ Edyta Protasiuk $^{1}$ • \\ Teresa Szprengier-Juszkiewicz ${ }^{1}$. Jan Żmudzki ${ }^{1}$
}

Received: 11 February 2015 / Accepted: 4 November 2015 / Published online: 21 November 2015

(C) The Author(s) 2015. This article is published with open access at Springerlink.com

\begin{abstract}
A method for the determination of a wide range residues of anti-inflammatory drugs (16 acidic non-steroidal anti-inflammatory drugs and four metamizole metabolites and five corticosteroids) has been was developed. In the first step of sample preparation, acetate buffer was added to minced muscle samples and 15-min ultrasound-assisted enzymatic hydrolysis was performed. Next, the samples were extracted twice with acetonitrile, freezed and analysed. The analytes were separated on a C18 column with a 25 -min gradient of methanol/acetonitrile (8:2) and $0.05 \mathrm{M}$ ammonium formate at pH 5.0 and determined by liquid chromatography-tandem mass spectrometry (LC-MS/MS). The method was validated according to the requirements described in the Commission Decision 2002/657/EC: linearity, precision (repeatability and within-laboratory reproducibility), accuracy, decision limit $\mathrm{CC} \alpha$ and detection capability $\mathrm{CC} \beta$ were calculated. The method developed fulfilled the performance criteria and can be used in the official control of veterinary drug residues in food of animal origin. The method was positively verified in the proficiency test and in the analysis of incurred material.
\end{abstract}

Keywords Non-steroidal anti-inflammatory drugs · Corticosteroids $\cdot$ Mass spectrometry $\cdot$ Muscle $\cdot$ Residues

Piotr Jedziniak

jedzi@piwet.pulawy.pl

Department of Pharmacology and Toxicology, National Veterinary Research Institute, Al. Partyzantów 57, 24-100 Puławy, Poland

\section{Introduction}

Non-steroidal anti-inflammatory drugs (NSAIDs) and glucocorticosteroids (GCs) are widely used in veterinary medicine as well as in treatment of diseases in food-producing animals. Despite its effectiveness, the important drawback of pharmacotherapy is drug residues in animal tissues. It became an important issue in the food safety. Potential toxicity of medicinal veterinary products has to be evaluated before the drug registration. When necessary, maximum residue limits (MRLs) in food are established. In the case of NSAIDs, MRL values were established in animal muscle for the following: salicylic acid (400 $\mu \mathrm{g} \mathrm{kg}^{-1}$ for turkey), flunixin $\left(10 \mu \mathrm{g} \mathrm{kg}^{-1}\right.$ for Equidae, $20 \mu \mathrm{g} \mathrm{kg}^{-1}$ for bovine, $50 \mu \mathrm{g} \mathrm{kg}^{-1}$ for porcine), meloxicam (20 $\mathrm{m} \mathrm{kg}^{-1}$ for bovine, caprine, porcine, rabbit, Equidae), metamizole (marker residue: 4-methylaminoantipyrine, $100 \mu \mathrm{g} \mathrm{kg}^{-1}$ for bovine, porcine, Equidae), diclofenac (5 $\mu \mathrm{g} \mathrm{kg}^{-1}$ for bovine, porcine), tolfenamic acid (50 $\mathrm{g} \mathrm{kg}^{-1}$ for bovine, porcine), carprofen $\left(500 \mu \mathrm{g} \mathrm{kg}^{-1}\right.$ for bovine, Equidae) and firocoxib (10 $\mathrm{g} \mathrm{kg}^{-1}$, Equidae). For GCs, MRLs for muscles are the following: dexamethasone $\left(0.75 \mu \mathrm{g} \mathrm{kg}^{-1}\right.$ for bovine, caprine, porcine, Equidae), betamethasone $\left(0.75 \mu \mathrm{g} \mathrm{kg}^{-1}\right.$ for bovine, porcine), methylprednisolone (10 $\mu \mathrm{g} \mathrm{kg}^{-1}$ for bovine, Equidae) and prednisolone $\left(4 \mu \mathrm{g} \mathrm{kg}^{-1}\right.$ for bovine, Equidae) (European Commission 2010). For some other compounds (phenylbutazone, oxyphenbutazone, ibuprofen, naproxen, mefenamic acid), recommended concentration (5 or $10 \mu \mathrm{g} \mathrm{kg}^{-1}$ for all species) has been proposed (CRL Guidance Paper 2007). Important features of AI metabolism (like formation of glucuronides) impose the necessity of the application of a hydrolysis step in the sample preparation (Jedziniak et al. 2013a). In some cases, a deconjugation step is necessary, e.g. carprofen, when the marker residue was expressed as a "sum of 
carprofen and carprofen glucuronide conjugate" (European Commission 2010).

In the case of glucocorticosteroids, a significant part of residues are conjugated as glucuronide (e.g. $50 \%$ of dexamethasone residues) (Vree et al. 1999). Some medicines like phenylbutazone and diclofenac have limited stability in samples and during the sample preparation (Reddersen and Heberer 2003; European Food Safety Authority 2013).

Residues of anti-inflammatory drugs (AIs), both NSAIDs and GCs, have been found in food in recent years in relatively low percentage. In the years 2007-2010, the proportion of non-compliant samples in the European Union remained relatively constant (around 0.1-0.2 \%) (European Food Safety Authority 2012). Nevertheless, the detection of phenylbutazone residues (NSAID which is not authorised for use in foodproducing animals), found in the horse meat, was an important issue in the EU in 2012 (European Food Safety Authority 2013). In the group of GCs, dexamethasone was most commonly detected in bovines (21 non-compliant samples in 2009, representing $0.37 \%$ of total samples) (European Food Safety Authority 2011).

For the wider view on chemical contaminants in food, dozens or even hundreds of analytes were included in multiclass methods based on LC-MS/MS. Due to the variety of chemical properties, only simple sample preparation can be used, which is effective in the terms of analyte coverage but can generate some difficulties. One of them is the matrix effect, phenomena (ion suppression or ion enhancement) caused by matrix constituents present in the sample (Matuszewski 2006).

Most of the published LC-MS/MS methods cover a wide range of NSAIDs or GCs. Recently, thanks to more sensitive and faster mass spectrometers, AIs have been included in the multiclass-multiresidue methods with LC-MS/MS (GeisAsteggiante et al. 2012; Robert et al. 2013) or LC-TOF (Ortelli et al. 2009; Peters et al. 2009). Multiclass methods cover dozen of analytes, but their sample preparation has to be very generic; such methods cannot cover the analysis of conjugated analytes.

It should be emphasised that only few methods allow to determine both groups of analytes and include hydrolysis of phase II metabolites (e.g. glucuronides) in the sample preparation.

Chrusch et al. published the procedure for the simultaneous determination of 29 veterinary drugs (NSAIDs, GCs and anabolic steroids) in animal tissues based on acidic hydrolysis, multistage solid-phase extraction (SPE) clean-up and different LC conditions for specific groups of analytes (Chrusch et al. 2008). Recently, basic hydrolysis and clean-up with mixedmode cation-exchange cartridge were used for the simultaneous determination of corticosteroids, anabolic steroids and basic NSAIDs in milk and muscles (Kaufmann et al. 2014). An important drawback of the above methods is multistep sample preparation based on the SPE.
The authors want to share their experience in the determination of NSAIDs in animal tissues ( Jedziniak et al. 2010, Jedziniak et al. 2013b, Olejnik et al. 2013) and develop a new method with wider range of analytes (both metamizole metabolites and "acidic" NSAIDs and GC), enzymatic hydrolysis step and simple sample preparation. According to the best authors' knowledge, methods for the simultaneous determination of NSAIDs and GCs with enzymatic hydrolysis were not published.

Such approach ensures faster and cheaper analysis and allows to determine conjugated analytes, what is not possible with previously published procedures.

\section{Material and Methods}

\section{Reagents and Sorbents}

Acetonitrile $(\mathrm{ACN})$ and methanol $(\mathrm{MeOH})$, both LC-MS grade, were obtained from J.T. Baker, Germany. Ammonium formate, HPLC grade, was from LGC Standard, UK. Sodium acetate, puriss p.a. was purchased from $\mathrm{POCH}$, Poland. Acetic acid, formic acid (all LC-MS grade), $\beta$-glucuronidase from Helix pomatia (HP-2) and ascorbic acid (puriss p.a.) were from Sigma-Aldrich, Germany. Ultrapure water (resistance $>18 \mathrm{~m} \Omega$ ) was obtained from Milli-Q system (Millipore, France).

The analytical standards were supplied by the following manufacturers: diclofenac (DC), flunixin meglumine (FLU), carprofen (CPF), mefenamic acid (MEF), tolfenamic acid (TOL), meloxicam sodium (MEL), naproxen (NAP), celecoxib (CELE), flufenamic acid (FLUF), ibuprofen (IBU), ibuprofen glucuronide (IBU-GLU), dexamethasone (DEX), betamethasone (BMT), flumethasone (FLUM), prednisolone (PRED), carprofen-d3 (CPF-d3), meloxicam-d3 (MEL-d3) Sigma-Aldrich, Germany; 4-methylaminoantipyrine (4-MAA), 4-formylaminoantipyrine (4-FAA), 4-aminoantipyrine (4-AA), 4-acetylaminoantipyrine (4-AcAA), phenylbutazone (PBZ) and oxyphenbutazone monohydrate (OPB) - LGC Standard, UK; flurbiprofen (FLURB), flurbiprofen-d3 (FLURB-d3), indomethacin (IND), indomethacin-d4 (IND-d4), methylprednisolone (MPRED), dexamethasone-d4 (DEX-d4), ibuprofen- ${ }^{13} \mathrm{C} 3$ (IBU-13C3) - Cambridge Isotopes Laboratories, USA; and firocoxib (FIRO), fircoxib-d6 (FIRO-d6), phenylbutazone- ${ }^{13} \mathrm{C} 12$ (PBZ-13C12), oxyphenbutazone- ${ }^{13} \mathrm{C} 6$ (OPB-13C6) flunixin-d3 (FLU-d3) and 4-methylaminofenazone-d3 (4-MAA-d3) Witega, Germany. Niflumic acid (NIF), diclofenac- ${ }^{13} \mathrm{C} 6$ (DC13C6), mefenamic acid-d4 (MEF-d4) and tolfenamic acid- ${ }^{13} \mathrm{C} 6$ (TOL-13C6) were gifted by the European Union Reference Laboratory for Drug Residues in Berlin.

Cartridges and sorbents used for method development were the following: C18 (500 mg, $3 \mathrm{~mL}$, Avantor, USA); C18 bulk sorbent (Avantor, USA); C8 (500 mg, $3 \mathrm{~mL}$, Avantor, USA); Oasis HLB (60 mg, 3 mL, Waters, USA); Strata X, Strata X-C, 
Strata XL and Strata XL-A (all $60 \mathrm{mg}, 3 \mathrm{~mL}$, Phenomenex, USA); HybridSPE (100 mg, $3 \mathrm{~mL}$, Supelco, USA); and primary secondary amine (PSA, Supelco, USA).

\section{Standard Solutions, Buffers and Samples}

Stock standard solutions $\left(1000 \mu \mathrm{g} \mathrm{mL} \mathrm{m}^{-1}\right)$ were prepared by weighing of $10.0 \mathrm{mg}$ of each analyte and dissolving in $10.0 \mathrm{~mL}$ of methanol (stable for 12 months). Working standard solutions $\left(100 \mu \mathrm{g} \mathrm{mL}^{-1}\right)$ were prepared by the dilution of the proper solutions with methanol and were stable for 6 months.

Three mixed standard solutions were prepared by the dilution of suitable aliquots of working standard solutions $\left(100 \mu \mathrm{g} \mathrm{mL}^{-1}\right)$ and used for a muscle sample spiked on three levels (Table 2). The first one contained $0.25 \mu \mathrm{g} \mathrm{mL}^{-1}$ of PBZ and $\mathrm{OPB}$ and was stable for 1 month. The second one contained $0.25 \mu \mathrm{g} \mathrm{mL}^{-1}$ of DC; $2.5 \mu \mathrm{g} \mathrm{mL}^{-1}$ of TOL; $1 \mu \mathrm{g} \mathrm{mL}^{-1}$ of MEL; $0.2 \mu \mathrm{g} \mathrm{mL} \mathrm{m}^{-1}$ of PRED; $0.0375 \mu \mathrm{g} \mathrm{mL}^{-1}$ of DEX; BMT; $5 \mu \mathrm{g} \mathrm{mL}^{-1}$ of 4-MAA; and $0.5 \mu \mathrm{g} \mathrm{mL}^{-1}$ of FLU, MEF, NAP, IBU, FIRO, CELE, FLUF, FLURB, IND, NIF, FLUM, MPRED, TRIAM, 4-FAA, 4-AA and 4-AcAA and was stable up to 6 months. The third standard (the mixed solution of internal standards (ISs)) contained $2.0 \mu \mathrm{g} \mathrm{mL} \mathrm{m}^{-1}$ of each IS (DEX-d4, DC-13C6, PBZ-13C12, FIRO-d6, FLURBd3, FLU-d3, IBU-d3, IND-d4, CPF-d3, MEF-d4, TOL-13C6, MEL-d3, 4-MMA-d3, OXPBZ-13C6) and was stable for 6 months. All standards solutions were stored at $2-10{ }^{\circ} \mathrm{C}$ and used for spiking muscle samples at three levels.

Acetate buffer used in the enzymatic hydrolysis was prepared by dissolving sodium acetate $(2.7 \mathrm{~g})$ and ascorbic acid $(0.17 \mathrm{~g})$ in water $(100 \mathrm{~mL})$. The $\mathrm{pH}$ was adjusted to 4.5 with acetic acid.

A blank muscle samples (bovine, swine, horse) were collected from different regions of Poland by veterinary inspection.

\section{Equipment}

In the sample preparation, vortex mixer (IKA, Germany), nitrogen evaporator (VLM, Germany), freezer (Liebherr, Germany), laboratory centrifuge (Sigma, Germany) and laboratory glassware and pipettes were used. Syringe filters (Puradisc PTFE $0.45 \mu \mathrm{m}$ ) were from Whatman, UK. The analysis was performed using Agilent 1200 liquid chromatograph (Agilent Technologies, Germany) connected to ABSciex QTRAP 5500 mass spectrometer (ABSciex, Canada), controlled by Analyst 1.5 software.

\section{Sample Preparation}

The muscle samples $(2 \pm 0.01 \mathrm{~g})$ were weighed into a $50-\mathrm{mL}$ polypropylene centrifuge tube. The volume $20 \mu \mathrm{L}$ of IS solution was added, and the sample was vortex-mixed and allowed to rest for $10 \mathrm{~min}$. Then, acetate buffer $(4 \mathrm{~mL})$ and $\beta$ glucuronidase $(50 \mu \mathrm{L})$ were added. The sample was vigorously mixed and sonicated $\left(15 \mathrm{~min}, 37^{\circ} \mathrm{C}\right)$. Next, the sample was extracted with two portions of ACN $(5 \mathrm{~mL})$ by vortex mixing $(1 \mathrm{~min})$ and centrifuged $\left(4120 \times \mathrm{g}, 20 \mathrm{~min},-5^{\circ} \mathrm{C}\right)$. The combined extracts $(10 \mathrm{~mL})$ were transferred into a $10-\mathrm{mL}$ glass tube and placed in the freezer $\left(-20^{\circ} \mathrm{C}\right)$ for $60 \mathrm{~min}$. The upper layer of the extract $(2 \mathrm{~mL})$ was collected and evaporated to dryness in the nitrogen stream (at $40{ }^{\circ} \mathrm{C}$ ) and reconstituted in $1 \mathrm{~mL}$ of mobile phase $\left(\mathrm{MeOH} / \mathrm{ACN} / \mathrm{H}_{2} \mathrm{O}, 0.5: 0.5: 9, v / v / v\right)$. The sample was filtered through syringe filters, transferred into the autosampler vial and analysed by LC-MS/MS.

\section{LC-MS/MS Analysis}

The chromatographic separation was carried out on a Luna C18 column ( $3 \mu \mathrm{m}, 4.6 \times 150 \mathrm{~mm}$, Phenomenex, USA) connected with a $\mathrm{C} 18$ guard column $(2.0 \times 4 \mathrm{~mm}$, Phenomenex, USA). The gradient was applied with $\mathrm{MeOH} / \mathrm{ACN}(8+2, v+v$, containing $0.1 \%$ formic acid-phase A) and $0.01 \mathrm{M}$ ammonium formate, $\mathrm{pH} 5.0$ (phase $\mathrm{B}$ ). The initial conditions of the gradient kept until 5 min were $15 \% \mathrm{~A}$ and $85 \% \mathrm{~B}$. The phase A content was increased to $32 \%$ at $5.5 \mathrm{~min}$, and such conditions were maintained until $12 \mathrm{~min}$. Next, phase A content was increased to $48 \%$ at $12.5 \mathrm{~min}$. From 12.5 to $16 \mathrm{~min}$, the content of phase A was increased to $70 \%$, and such conditions were maintained until $20 \mathrm{~min}$. From $20.5 \mathrm{~min}$, the system was re-equilibrated with the initial composition of the mobile phase. The total run time of the method was $24 \mathrm{~min}$. The flow rate was $0.8 \mathrm{~mL} \mathrm{~min}^{-1}$, the injection volume was $50 \mu \mathrm{L}$, and the column temperature was $30^{\circ} \mathrm{C}$.

Mass spectrometry analysis was performed using electrospray (electrospray ionization (ESI), polarity switching) in multiple reaction monitoring (MRM) mode. The ESI interface conditions were optimised as follows: the source temperature $600{ }^{\circ} \mathrm{C}$, capillary voltage $-4.5 \mathrm{kV}$ in negative mode and $+5.5 \mathrm{kV}$ in positive mode, curtain gas $30 \mathrm{psi}$, nebuliser gas $60 \mathrm{psi}$ and turbo heater gas 20 psi. For each analyte, two fragmentation reactions were monitored whereas one was monitored for ISs. Detailed MS conditions are described in Table 1.

\section{Verification of Enzymatic Hydrolysis Efficiency}

The blank muscle samples (bovine, swine, horse muscle, $n=3$ ) were spiked with IBU-GLU standard at the level of $50 \mu \mathrm{g} / \mathrm{kg}$. The samples were determined with a developed procedure, and IBU concentration was measured.

\section{Development of Extract Clean-Up (SPE, Dispersive SPE, Freezing)}

The extracts $(n=3)$ of spiked samples were passed through SPE cartridges (C18, C8, HLB, Strata X, Strata X-C, Hybrid) and eluate was collected. The cartridges were vacuum dried for $1 \mathrm{~min}$, and eluate was evaporated to dryness $\left(\mathrm{N}_{2}\right.$, 
$40{ }^{\circ} \mathrm{C}$ ). The dry residue was reconstituted in $1 \mathrm{~mL}$ of mobile phase $\left(\mathrm{MeOH} / \mathrm{ACN} / \mathrm{H}_{2} \mathrm{O}, 0.5: 0.5: 9, v / v / v\right)$ and analysed by LC-MS/MS. For verification of dispersive SPE, the following sorbents: C18 (100 mg) and C18 with PSA (both $100 \mathrm{mg}$ ) were added to $2 \mathrm{~mL}$ of extracts, vortex-mixed $(1 \mathrm{~min})$ and centrifuged $(14,000 \mathrm{rpm})$. The $1 \mathrm{~mL}$ of extract was evaporated to dryness $\left(\mathrm{N}_{2}, 40^{\circ} \mathrm{C}\right)$, reconstituted in $1 \mathrm{~mL}$ of mobile phase and analysed by LC-MS/MS.For verification of freezing effectives, the spiked extracts $(10 \mathrm{~mL})$ were and placed in the freezer $\left(-20^{\circ} \mathrm{C}\right)$ for $60 \mathrm{~min}$. The upper layer of the extract $(2 \mathrm{~mL})$ was collected and evaporated to dryness in the nitrogen stream (at $40{ }^{\circ} \mathrm{C}$ ) and reconstituted in $1 \mathrm{~mL}$ of mobile phase and analysed by LC-MS/MS.

\section{Validation}

The method was validated as a confirmatory procedure according to Commission Decision 2002/657/EC (European Commission 2002), and all criteria for confirmation (requirements for retention time and criteria for ion ratios) were taken from the above document. Standard calibration curves were prepared by the injection of mixed standard solutions on five concentration levels and plotting ratios of recorded peak areas of each analyte and adequate ISs versus concentration. In the selectivity study, 20 blank muscle samples from animals (bovine, swine, horse) from different regions of Poland were analysed. The matrix effect was
Table 1 MS/MS parameters for determination of AIs in muscle (ABSciex QTRAP 5500)

\begin{tabular}{|c|c|c|c|c|c|}
\hline Analyte & $\begin{array}{l}\text { Parent } \\
\text { ion }(\mathrm{m} / \mathrm{z})\end{array}$ & $\begin{array}{l}\text { Declustering } \\
\text { potential }(\mathrm{eV})\end{array}$ & $\begin{array}{l}\text { Daughter } \\
\text { ions }(\mathrm{m} / \mathrm{z})\end{array}$ & $\begin{array}{l}\text { Collision } \\
\text { energy }(\mathrm{eV})\end{array}$ & $\begin{array}{l}\text { Internal } \\
\text { standard }\end{array}$ \\
\hline \multicolumn{6}{|l|}{ ESI+ } \\
\hline 4-Acetylaminoantipyrine & 246 & 192 & $104,83^{\mathrm{a}}$ & 31,42 & 4-MAA-d3 \\
\hline 4-Aminoantipyrine & 204 & 185 & $83,56^{\mathrm{a}}$ & 42,19 & 4-MAA-d3 \\
\hline 4-Formylaminoantipyrine & 232 & 191 & $104,83^{\mathrm{a}}$ & 29,27 & 4-MAA-d3 \\
\hline 4-Methylaminoantipyrine & 218 & 170 & $97,56^{\mathrm{a}}$ & 17,44 & 4-MAA-d3 \\
\hline Celecoxib & 382 & 290 & $362^{\mathrm{a}}, 282$ & 40,45 & FIRO-d6 \\
\hline Diclofenac & 296 & 50 & $250^{\mathrm{a}}, 215$ & 17,27 & DC-13C6 \\
\hline Firocoxib & 337 & 100 & $283^{\mathrm{a}}, 237$ & 14,23 & FIRO-d6 \\
\hline \multicolumn{6}{|l|}{ ESI- } \\
\hline 5-Hydroxyflunixin & 311 & -51 & 267,227 & $-22,-33$ & FLU-d3 \\
\hline Betamethasone & 437 & -80 & 361,307 & $-25,-40$ & DEX-d4 \\
\hline Carprofen & 272 & -40 & $228,226^{\mathrm{a}}$ & $-17,-37$ & CPF-d3 \\
\hline Dexamethasone & 437 & -65 & $361^{\mathrm{a}}, 307$ & $-25,-42$ & DEX-d4 \\
\hline Diclofenac & 294 & -80 & $250^{\mathrm{a}}, 214$ & $-28,-16$ & DC-13C6 \\
\hline Flufenamic acid & 280 & -157 & $236^{\mathrm{a}}, 216$ & $-24,-26$ & FLU-d3 \\
\hline Flumethasone & 455 & -75 & $379^{\mathrm{a}}, 325$ & $-25,-31$ & DEX-d4 \\
\hline Flunixin & 295 & -51 & $251^{\mathrm{a}}, 191$ & $-25,-41$ & FLU-d3 \\
\hline Flurbiprofen & 243 & -70 & $199^{\mathrm{a}}, 175$ & $-10,-12$ & FLURB-d3 \\
\hline Ibuprofen & 205 & -20 & 161,159 & $-9,-11$ & IBU-13C3 \\
\hline Ibuprofen glucuronide & 381 & -20 & 193,205 & $-8,-12$ & IBU-13C3 \\
\hline Indomethacin & 356 & -97 & $312^{\mathrm{a}}, 297$ & $-12,-27$ & IND-d4 \\
\hline Mefenamic acid & 240 & -60 & $196^{\mathrm{a}}, 192$ & $-24,-40$ & MEF-d4 \\
\hline Meloxicam & 350 & -55 & $286^{\mathrm{a}}, 146$ & $-17,-25$ & MEL-d3 \\
\hline Methylprednisolone & 419 & -79 & $343^{\mathrm{a}}, 309$ & $-25,-43$ & DEX-d4 \\
\hline Naproxen & 229 & -50 & $185^{\mathrm{a}}, 170$ & $-14,-20$ & FLU-d3 \\
\hline Niflumic acid & 281 & -155 & $237^{\mathrm{a}}, 217$ & $-23,-30$ & FLU-d3 \\
\hline Oxyphenbutazone & 323 & -56 & $295^{\mathrm{a}}, 134$ & $-25,-35$ & OPB-13C6 \\
\hline Phenylbutazone & 307 & -70 & $279^{\mathrm{a}}, 131$ & $-26,-28$ & PBZ-13C12 \\
\hline Prednisolone & $\begin{array}{l}405 \\
329\end{array}$ & $\begin{array}{l}-80 \\
-200\end{array}$ & $329^{\mathrm{a}}, 295^{\mathrm{a}}$ & $-23,-25$ & DEX-d4 \\
\hline Tolfenamic acid & 260 & -74 & $227,216^{\mathrm{a}}$ & $-14,-22$ & TOL-13C6 \\
\hline Triamcinolone acetonide & 479 & -70 & $413^{\mathrm{a}}, 337$ & $-30,-20$ & DEX-d4 \\
\hline
\end{tabular}

ESI+ positive ionization, ESI negative ionization)

${ }^{\mathrm{a}}$ Transition used for quantification 


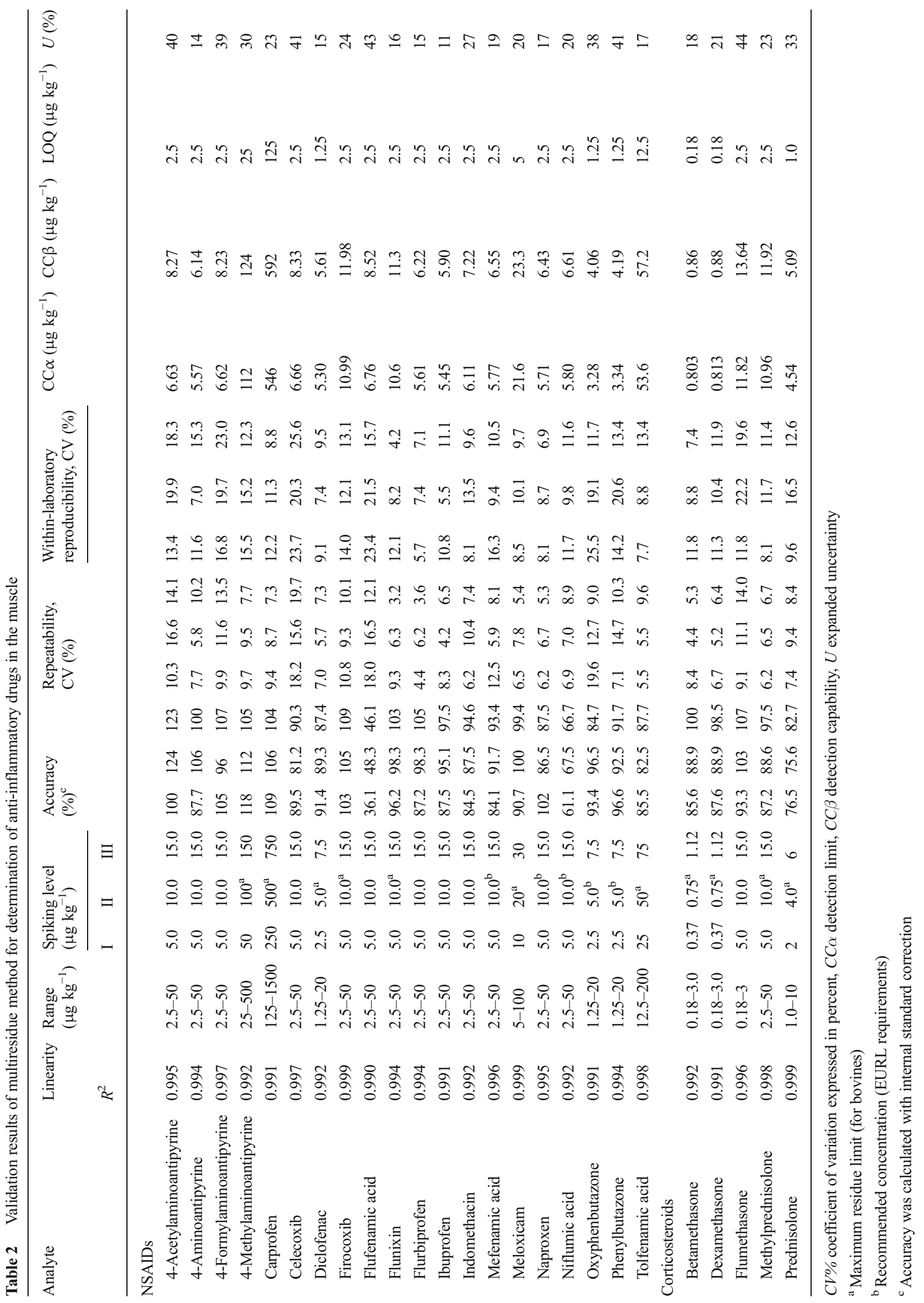


verified by the post-extraction addition method. Blank muscle samples (bovine, swine, horse muscles, each of $n=6)$ were spiked with standard solution at the spiking level II (Table 2) at the end of the analytical procedure (just before final evaporation) and determined. The ratios of analytes' peak areas in the post-extraction samples and injected working standard solutions were calculated and expressed as "percents" (relative matrix effect). The above calculation was performed using correction for IS (IScorrected relative matrix effect).

In the accuracy and precision study, muscle samples (previously determined as blank ones) were spiked with AIs on three levels: 0.5, 1 and 1.5 times the MRL for 4MAA, FLU, MEL, TOL, DC, DEX, BET, PRED, CPF and MPRED. For other compounds, spiking levels were chosen by the authors considering the concentration proposed by European Union Reference Laboratories (Table 2) or provisional sensitivity of the method. For the repeatability study, three series of swine muscle were analysed under the identical conditions (six samples for each spiking level). Standard deviation (SD) and coefficient of variation (CV, \%) were calculated for each level. The withinlaboratory reproducibility was obtained by the analysis of two additional series (on three levels) in reproducibility conditions (another technician, two different days) of bovine and horse muscles, and overall SD and CV were calculated. The overall mean concentrations obtained in the reproducibility study were used to calculate accuracy (\%). Decision limits $(\mathrm{CC} \alpha)$ and detection capability $(\mathrm{CC} \beta)$ were calculated using within-laboratory reproducibility results, according to the procedure described in the Commission Decision 2002/657/EC (European Commission 2002) and the guidance paper (CRL Guidance Paper 2007). $C C \alpha$ and $C C \beta$ were calculated according to the following equation:

$\mathrm{CC} \alpha=\mathrm{MRL}$ (or 1st spiking level) $+1.64 \times \mathrm{SD}_{\mathrm{WLR}}$

$\mathrm{CC} \beta=\mathrm{CC} \alpha+1.64 \times \mathrm{SD}_{\mathrm{WLR}}$

MRL (or 1st spiking level)

- concentration equal to MRL value or 1st spiking level

$\mathrm{SD}_{\mathrm{WLR}}-$ standard deviation of within

-laboratory reproducibility at MRL/1st spiking level

Limit of quantitation was established as the lowest point of matrix calibration curve. The uncertainty $(U)$ was calculated as the ratio of coverage factor $(k=2)$ and standard deviation (SD) of within-laboratory reproducibility:

$U=k^{*} \mathrm{SD}_{\text {within-laboratory reproducibility }}$

and expressed in percent.
Fig. 1 Ion chromatogram (transitions used for quantification) obtained from bovine muscle sample spiked with anti-inflammatory drugs at level II (4-AA 4-aminofenazone, 4-AcAA acetylaminofenazone, 4-FAA 4formylaminofenazone, 4-MAA 4-methylaminofenazone, $P R E D$ prednisolone, MEL meloxicam, MPRED methylprednisolone, BMT betamethasone, $D E X$ dexamethasone, FLUM flumethasone, NAP naproxen, $O P B$ oxyphenbutazone, $F L U$ flunixin, $N I F$ niflumic acid, $F I R O$ firocoxib, FLURB flurbiprofen, $C P F$ carprofen, $D C$ diclofenac, $I N D$ indomethacin, $P B Z$ phenylbutazone, FLUF flufenamic acid, $I B U$ ibuprofen, $M E F$ mefenamic acid, $T O L$ tolfenamic acid, CELE celecoxib)

\section{Methods' Comparison}

The incurred material (muscle samples: pork chop, pork neck, pork shoulder) was collected from pig euthanised $24 \mathrm{~h}$ after administration of Dexafort ${ }^{\mathrm{TM}}$ (DEX, dose $0.6 \mathrm{mg} \mathrm{kg}^{1}$, b.w., I.V.) The experiment was carried out in compliance with the Decision No 2/2012 of the Local Animal Experimentation Ethics Committee in Lublin, Poland.

The collected muscle samples (pork chop, pork neck, pork shoulder, each of $n=3$ ) were analysed with the described procedure. The muscle samples were also analysed according to the procedure for determination of corticosteroids (Van den Hauwe et al. 2002).

\section{Results and Discussion}

\section{LC-MS/MS Conditions}

During the development of the method, we used our previous experiences with the determination of NSAIDs in milk, where negative ionisation was more suitable for most of acidic NSAIDs and positive ionisaton showed better signal to noise values for metamizole metabolites, coxibs and some NSAIDs like DC (Jedziniak et al. 2012). GCs also can be detected in both polarities, but we decided to determine stable negatively ionised formic adducts of the analytes [ $\mathrm{M}+$ formate $]^{-}$according to the method published by Van de Hauwe et al. (2002). Although formic acid seems to be a proper choice as an additive in mobile phase for acidic analytes, it was not suitable in the case of metamizole metabolites (wide and tailing peaks). Thus, a composition of the mobile phase (MeOH/ACN and $0.05 \mathrm{M}$ ammonium formate solution at $\mathrm{pH}$ 5.0) was a compromise between peak shape, sensitivity and time of analysis.

The separation of DEX and BMT (two isomers with the same MRM transitions) was an additional challenge. In recent publications, two strategies were observed: first, separation with carbon-loaded column ( $\mathrm{Li}$ et al. 2010) or C18 column with relatively long runtimes (Chen et al. 2010). Shorter separation time can be achieved with UHPLC systems (Herrero et al. 2012; Tölgyesi et al. 2012; Deceuninck et al. 2013). Our early experiences show that $\mathrm{C} 18$ or $\mathrm{C} 8$ columns (Intersil from GLScience, Luna and Kinetex from Phenomenex, Halo from 


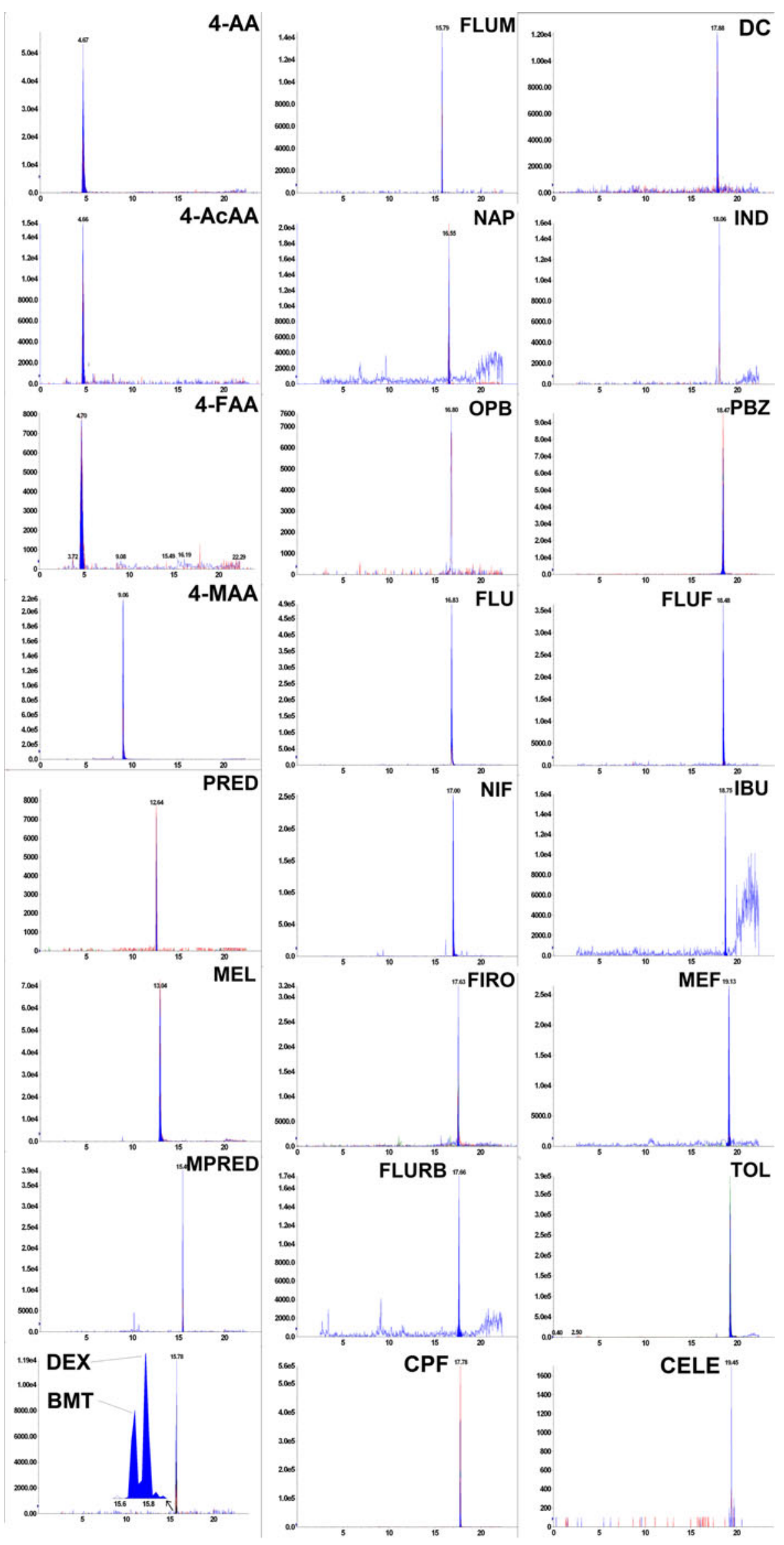


AMT $)$ in classic MS format $(150 \times 2.1 \mathrm{~mm}, 3 \mu \mathrm{m})$ and different gradient profiles separate both compounds insufficiently with described mobile phase and gradient. For this reason, we adopted wider column $(150 \times 4.6 \mathrm{~mm}, 3 \mu \mathrm{m})$ with higher flow rate $\left(0.8 \mathrm{~mL} \mathrm{~min}^{-1}\right)$ according to the experience of Malone et al. (2009) (Fig. 1).

\section{Sample Preparation Development—Enzymatic Hydrolysis}

The inclusion of deconjugation step, i.e. enzymatic or chemical hydrolysis, was an important assumption of the method.
Although some authors use acidic (Chrusch et al. 2008) or alkaline hydrolysis (Chen et al. 2010; Kaufmann et al. 2014), in most published methods, enzymatic hydrolysis with beta-glucuronidase was used (Jedziniak et al. 2010; Van den Hauwe et al. 2002). An important advantage of using chemical hydrolysis is the effectiveness of the reaction, whereas enzymatic hydrolysis is more selective and ensures milder conditions than chemical one, what results in cleaner extracts (Wang et al. 2011). Optimisation of this step of sample preparation requires incurred material and was performed in some previous studies (Van den Hauwe et al. 2002). For DEX deconjugation step in liver samples, 4-h enzymatic hydrolysis
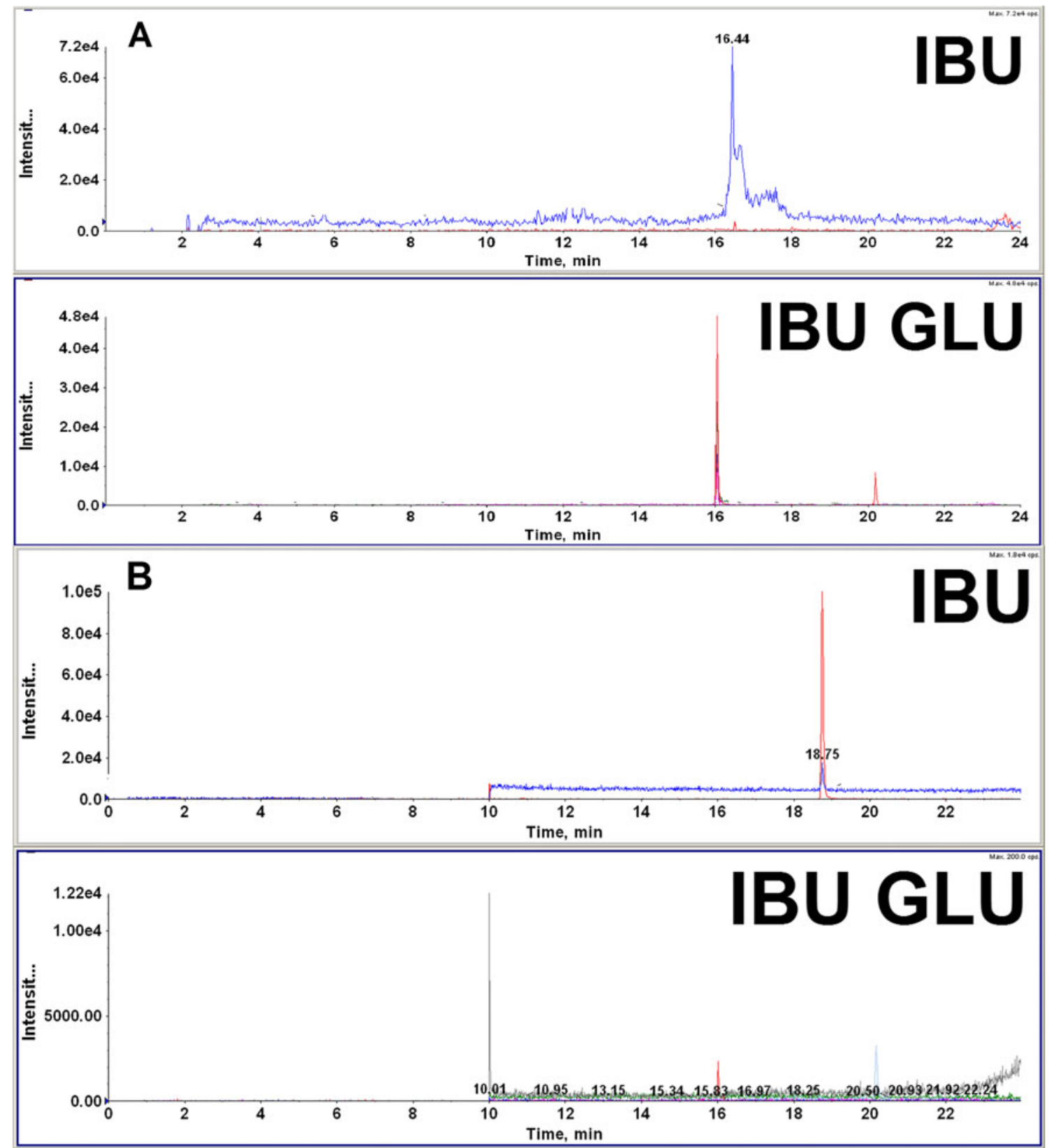

Fig. 2 Ion chromatogram obtained from swine muscle samples spiked with ibuprofen glucuronide (IBU-GLU): a sample preparation without enzymatic hydrolysis and $\mathbf{b}$ sample preparation with enzymatic hydrolysis 
Fig. 3 Analytes' extraction recoveries using different sample preparations (different sorbents and freezing used as clean-up step). Recovery rate was calculated without internal standard correction

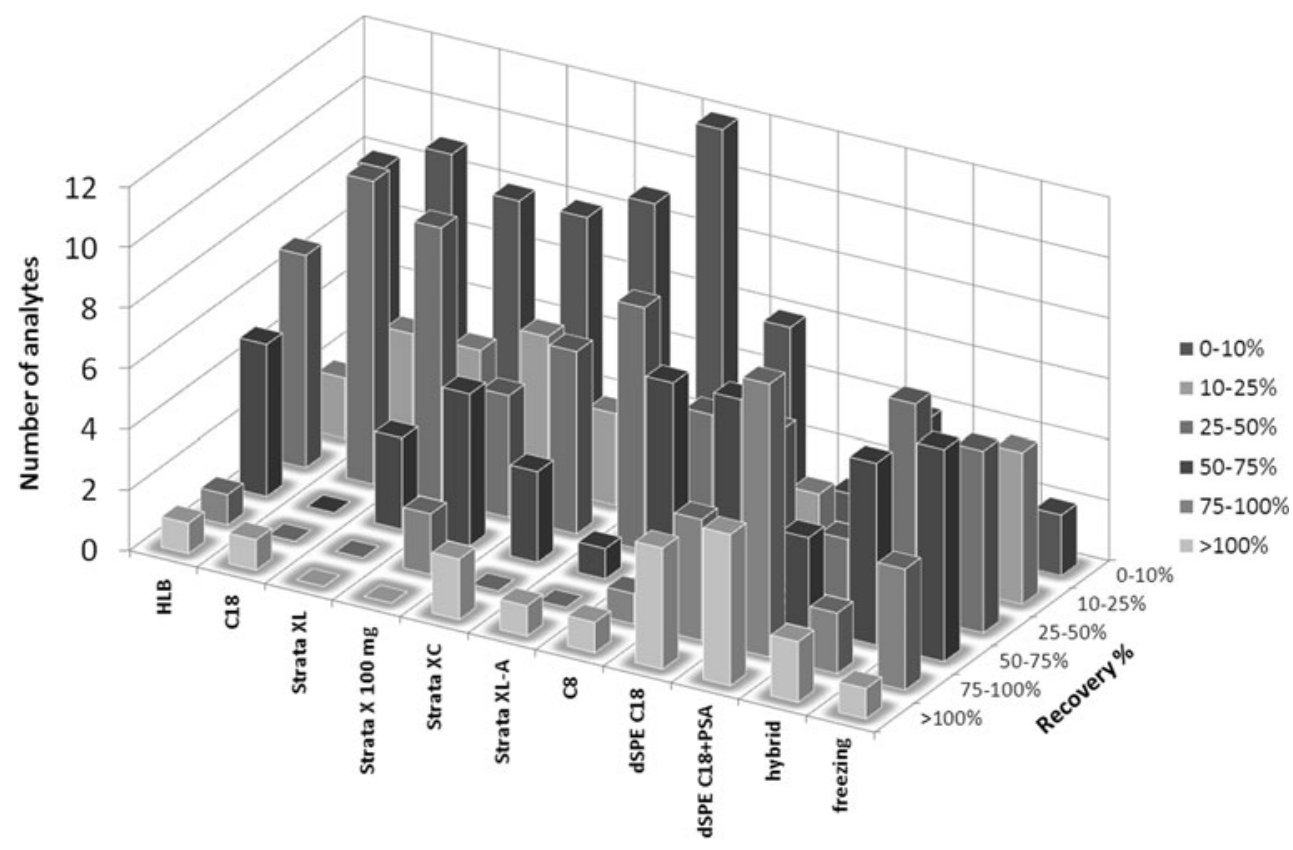

at $\mathrm{pH}$ of 5.2 and at $40{ }^{\circ} \mathrm{C}$ was necessary. In our procedure, the time of hydrolysis was shortened to $15 \mathrm{~min}$ at $37{ }^{\circ} \mathrm{C}$ using ultrasonication (Alvarez-Sánchez et al. 2009). Verification of hydrolysis efficiency was performed with the analysis of blank samples spiked with IBU-GLU. As a result, IBU presence was confirmed and reduction of IBU-GLU peak area (99\%) was observed (Fig. 2).

\section{Sample Preparation Development}

An important drawback of enzymatic hydrolysis is the increase in matrix constituents that can interfere with analytes, requiring a more effective clean-up (Wang et al. 2011). Although SPE was widely used in the NSAID and GC analysis (Antignac et al. 2001; Gentili et al. 2012), this kind of clean-up (loading sample, cleaning solvent and elution) was not verified in this study due to longer time of sample preparation and poor retention of metamizole metabolites on the reversedphase sorbents (Jedziniak et al. 2012). SPE cartridges (C18, C8, Oasis HLB, Strata X, Strata X-C, Strata XL, Strata XL-A, HybridSPE) were used only as the filter of ACN extract (the extract was passed through the cartridge). Additionally, the effectiveness of dispersive SPE with C18 and PSA sorbent was evaluated. The results (Fig. 3) show relatively wide range

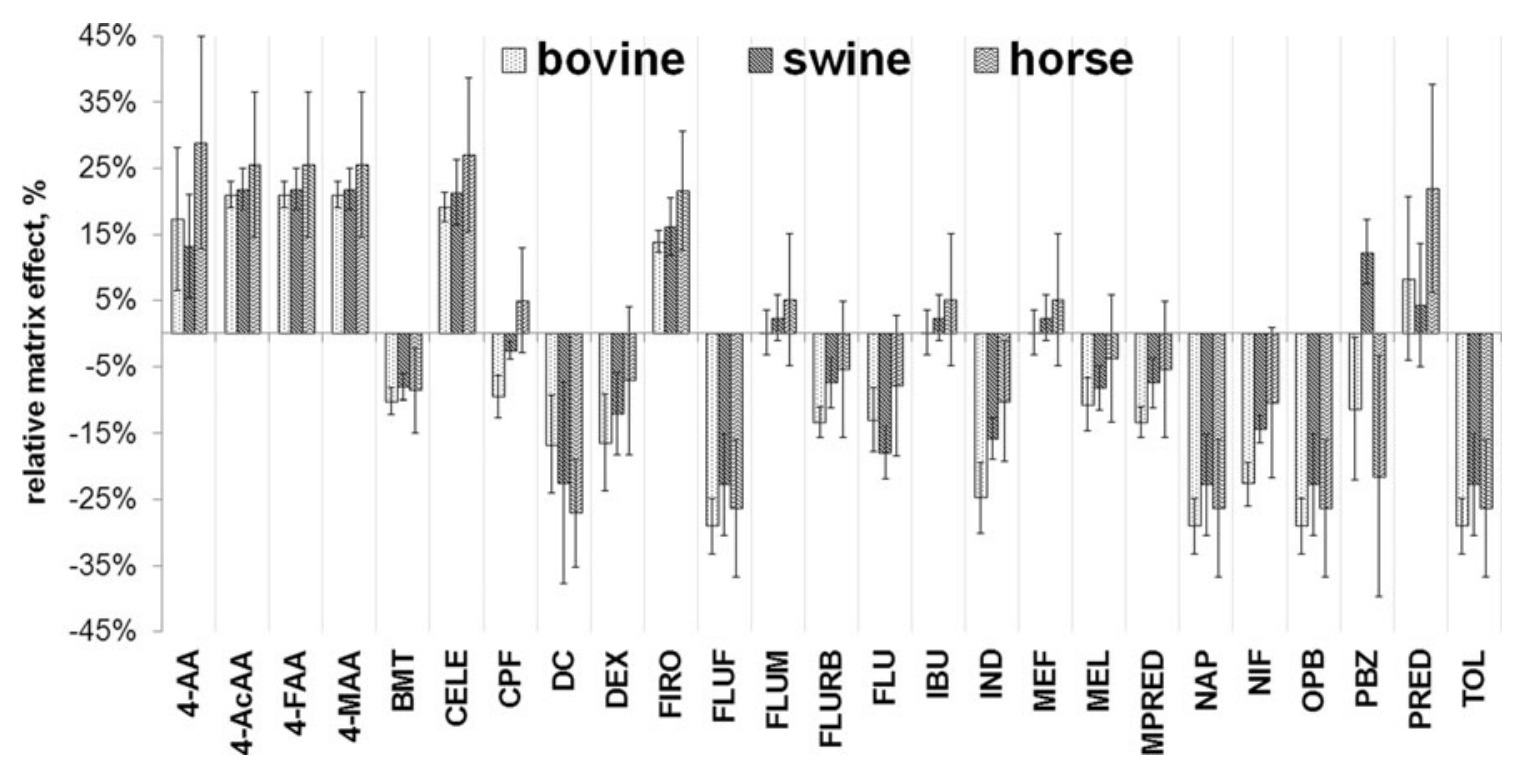

Fig. 4 Internal standard-corrected matrix effect in bovine, swine and horse muscle samples (mean and standard deviation) 
Table 3 Results of the muscle sample analysis collected from the pigs treated with anti-inflammatory drugs

\begin{tabular}{|c|c|c|c|c|c|c|c|}
\hline \multirow[t]{2}{*}{ Medicine used } & \multirow[t]{2}{*}{ Analyte } & \multicolumn{3}{|c|}{$\begin{array}{l}\text { Developed procedure } \\
\left(\mu \mathrm{g} \mathrm{kg}^{-1}, n=2, \text { mean } \pm \mathrm{SD}\right)\end{array}$} & \multicolumn{3}{|c|}{$\begin{array}{l}\text { Van den Hauwe et al. (2002) } \\
\left(\mu \mathrm{kg}^{-1}, n=2, \text { mean } \pm \mathrm{SD}\right)\end{array}$} \\
\hline & & Pork chop & Pork neck & Pork shoulder & Pork chop & Pork neck & Pork shoulder \\
\hline $\begin{array}{l}\text { Dexafort }{ }^{\mathrm{TM}} \text { (dexamethasone, } \\
\text { dose } 0.6 \mathrm{mg} / \mathrm{kg} \text {, b.w., I.V.) }\end{array}$ & Dexamethasone & $0.24 \pm 0.07$ & $0.21 \pm 0.03$ & $0.37 \pm 0.03$ & $0.39 \pm 0.03$ & $0.29 \pm 0.04$ & $0.36 \pm 0.02$ \\
\hline
\end{tabular}

of analytes' recoveries (extraction recoveries) for different cartridge/sorbent combinations. This observation confirms our experience that SPE or dSPE clean-up did not guarantee high recoveries for most analytes. Moreover, we also observed that a freezing step $\left(1 \mathrm{~h},-18^{\circ} \mathrm{C}\right)$ gives comparable recoveries to procedures with clean-up based on SPE or dispersive SPE (Fig. 3). Due to the simplicity of the sample preparation and its effectiveness, we decided to involve this step into the final procedure.

\section{Validation}

During verification of the selectivity of the method, we did not observed interference peaks in the retention time of analytes in analysed muscle samples. Nowadays, calculation of a matrix effect became the important part of validation in the method based on LC-MS/MS technique. Although performance criteria for this parameter were not established, many authors present ion suppression (or rarely ion enhancement) of developed methods. The results of the matrix effect study are presented in Fig. 4.

The obtained results show significant reduction of all analytes' peak areas (ion suppression). The calculated relative matrix effect was in the range of 28-77\%. The use of isotopelabelled ISs reduced the influence of this factor in quantitation: IS-corrected relative matrix effect was in the range -29$30 \% \%$ for all analytes with $\mathrm{CV}$ in the range $1-20 \%$.

The linearity of the method (correlation coefficient) and range of the method were on the acceptable level. The validation results show high accuracy for most analytes, in the range of $75-18 \%$. The lower accuracy was noticed for NIF (61$67 \%$ ) and FLUF (36-46\%) and slightly higher AcAA (100$124 \%$ ). The reason for this could be the lack of the proper labelled IS. The results of repeatability $(\mathrm{CV}=3.2-19.6 \%)$ and within-laboratory reproducibility $(\mathrm{CV}=4.2-25.6 \%)$ study show acceptable precision of determination of most compounds. Calculated $\mathrm{CC} \alpha$ and $\mathrm{CC} \beta$ values were slightly higher for MRL compounds and lower than recommended concentrations for those NSAIDs which are non-registered for food animals (Table 2). The results of validation suggest that, in the routine analyses, the use of matrix-matched calibration curves is preferable.

\section{Method's Verification}

Muscle samples taken from pig (pork chop, pork neck, pork shoulder) were analysed by the developed procedure with ultrasonic-assisted enzymatic hydrolysis with betaglucuronidase $\left(15 \mathrm{~min}, 37^{\circ} \mathrm{C}\right)$, and the results were compared with those obtained by analysing the muscle samples with procedure making use of 4-h enzymatic hydrolysis at $40{ }^{\circ} \mathrm{C}$ (Table 3 ). The results of analyses were comparable ( $t$ test, $P>0.05)$ and show efficiency of the developed procedure with determination of AI residues in incurred material.

The developed procedure was successfully verified in the FAPAS proficiency test (PBZ in equine muscle, nr 02231). The calculated $z$-score for results $\left(4.67 \mu \mathrm{g} \mathrm{kg}^{-1}\right.$ of PBZ) was in the range $-2<z<2(z$-score $=0.0)$.

\section{Conclusions}

The authors presented fast multiresidue method for the determination of AIs in animal muscles. It allows to determine a wide range (25) of NSAIDs and GCs in muscles on the levels required by the law and recommendation of European Union Reference Laboratory. An important advantage of the developed method is short time of enzymatic hydrolysis step and a simple sample clean-up. The results of method validation show its applicability as a screening and confirmatory procedure.

Acknowledgments This work was funded by the Ministry of Science and Higher Education of Poland (Project "Iuventus Plus" Nr IP2011 020371).

\section{Compliance with Ethics Requirements}

Conflict of Interest Piotr Jedziniak declares that he has no conflict of interest.

Piotr Jedziniak has received research grants funded by the Ministry of Science and Higher Education of Poland.

Małgorzata Olejnik declares that she has no conflict of interest.

Konrad Pietruk declares that he has no conflict of interest.

Edyta Protasiuk declares that she has no conflict of interest.

Teresa Szprengier-Juszkiewicz declares that she has no conflict of interest.

Jan Żmudzki declares that he has no conflict of interest. 
All institutional and national guidelines for the care and use of laboratory animals were followed. The animal study described in the paper was carried out in compliance with the Decision No 2/2012 of the Local Animal Experimentation Ethics Committee in Lublin, Poland.

Open Access This article is distributed under the terms of the Creative Commons Attribution 4.0 International License (http:// creativecommons.org/licenses/by/4.0/), which permits unrestricted use, distribution, and reproduction in any medium, provided you give appropriate credit to the original author(s) and the source, provide a link to the Creative Commons license, and indicate if changes were made.

\section{References}

Alvarez-Sánchez B, Priego-Capote F, Luque de Castro MD (2009) Ultrasound-enhanced enzymatic hydrolysis of conjugated female steroids as pretreatment for their analysis by LC-MS/MS in urine. Analyst 134:1416-22. doi:10.1039/b816283b

Antignac JP, Le Bizec B, Monteau F et al (2001) Multi-residue extractionpurification procedure for corticosteroids in biological samples for efficient control of their misuse in livestock production. J Chromatogr B Biomed Sci Appl 757:11-9

Chen D, Tao Y, Liu Z et al (2010) Development of a liquid chromatography-tandem mass spectrometry (LC-MS/MS) method for the quantification of glucocorticoid residues in edible tissues of swine, cattle, sheep, and chicken. Food Addit Contam Part A: Chem Anal Control Expo Risk Assess 27:1363-71. doi:10.1080/ 19440049.2010.492530

Chrusch J, Lee S, Fedeniuk R, Boison JO (2008) Determination of the performance characteristics of a new multi-residue method for nonsteroidal anti-inflammatory drugs, corticosteroids and anabolic steroids in food animal tissues. Food Addit Contam Part A: Chem Anal Control Expo Risk Assess 25:1482-96. doi:10.1080/ 02652030802273122

CRL Guidance Paper (2007) CRL guidance paper (7 December 2007)

Deceuninck Y, Bichon E, Monteau F et al (2013) Fast and multiresidue determination of twenty glucocorticoids in bovine milk using ultra high performance liquid chromatography-tandem mass spectrometry. J Chromatogr A 1294:76-86. doi:10.1016/j.chroma.2013.04.019

European Commission (2002) Commission Decision of 12 August 2002 implementing Council Directive 96/23/EC concerning the performance of analytical methods and the interpretation of results. Off $\mathrm{J}$ Eur Union L 221:1-29

European Commission (2010) Commission Regulation (EU) No 37/2010 of 22 December 2009 on pharmacologically active substances and their classification regarding maximum residue limits in foodstuffs of animal origin. Off J Eur Union L 15:1

European Food Safety Authority (2011) Report for 2009 on the results from the monitoring of veterinary medicinal product residues and other substances in live animals and animal products 1

European Food Safety Authority (2012) Report for 2010 on the results from the monitoring of veterinary medicinal product residues and other substances in live animals and animal products 1

European Food Safety Authority (2013) Joint statement of EFSA and EMA on the presence of residues of phenylbutazone in horse meat 1. EFSA J 11:1-45. doi:10.2903/j.efsa.2013.3190

Geis-Asteggiante L, Lehotay SJ, Lightfield AR et al (2012) Ruggedness testing and validation of a practical analytical method for $>100$ veterinary drug residues in bovine muscle by ultrahigh performance liquid chromatography-tandem mass spectrometry. J Chromatogr A 1258:43-54. doi:10.1016/j.chroma.2012.08.020
Gentili A, Caretti F, Bellante S et al (2012) Development and validation of two multiresidue liquid chromatography tandem mass spectrometry methods based on a versatile extraction procedure for isolating non-steroidal anti-inflammatory drugs from bovine milk and muscle tissue. Anal Bioanal Chem 404:1375-88. doi:10.1007/s00216-0126231-0

Herrero P, Borrull F, Pocurull E, Marcé RM (2012) Determination of glucocorticoids in sewage and river waters by ultra-high performance liquid chromatography-tandem mass spectrometry. J Chromatogr A 1224:19-26. doi:10.1016/j.chroma.2011.12.054

Jedziniak P, Szprengier-Juszkiewicz T, Olejnik M, Zmudzki J (2010) Determination of non-steroidal anti-inflammatory drugs residues in animal muscles by liquid chromatography-tandem mass spectrometry. Anal Chim Acta 672:85-92

Jedziniak P, Szprengier-Juszkiewicz T, Pietruk K et al (2012) Determination of non-steroidal anti-inflammatory drugs and their metabolites in milk by liquid chromatography-tandem mass spectrometry. Anal Bioanal Chem 403:2955-63

Jedziniak P, Olejnik M, Szprengier-Juszkiewicz T et al (2013a) Identification of flunixin glucuronide and depletion of flunixin and its marker residue in bovine milk. J Vet Pharmacol Ther. doi:10. 1111/jvp. 12035

Jedziniak P, Pietruk K, Sledzińska E et al (2013b) Rapid method for the determination of metamizole residues in bovine muscle by LC-MS/ MS. Food Addit Contam Part A: Chem Anal Control Expo Risk Assess 30:977-982. doi:10.1080/19440049.2013.787652

Kaufmann A, Butcher P, Maden K et al (2014) Determination of corticosteroids, anabolic steroids, and basic nonsteroidal anti-inflammatory drugs in milk and animal tissues. J AOAC Int 97:263-272. doi:10. 5740/jaoacint. 13-067

Li C, Wu Y, Yang T, Zhang Y (2010) Rapid simultaneous determination of dexamethasone and betamethasone in milk by liquid chromatography tandem mass spectrometry with isotope dilution. J Chromatogr A 1217:411-4. doi:10.1016/j.chroma.2009.12.015

Malone EM, Dowling G, Elliott CT et al (2009) Development of a rapid, multi-class method for the confirmatory analysis of antiinflammatory drugs in bovine milk using liquid chromatography tandem mass spectrometry. J Chromatogr A 1216:8132-40. doi: 10.1016/j.chroma.2009.04.078

Matuszewski BK (2006) Standard line slopes as a measure of a relative matrix effect in quantitative HPLC-MS. Bioanalysis 830:293-300. doi:10.1016/j.jchromb.2005.11.009

Olejnik M, Jedziniak P, Szprengier-Juszkiewicz T, Zmudzki J (2013) Influence of matrix effect on the performance of the method for the official residue control of non-steroidal anti-inflammatory drugs in animal muscle. Rapid Commun Mass Spectrom 27:437-42. doi: 10.1002/rcm.6467

Ortelli D, Cognard E, Jan P, Edder P (2009) Comprehensive fast multiresidue screening of 150 veterinary drugs in milk by ultraperformance liquid chromatography coupled to time of flight mass spectrometry. J Chromatogr B Analyt Technol Biomed Life Sci 877: 2363-74. doi:10.1016/j.jchromb.2009.03.006

Peters RJB, Bolck YJC, Rutgers P et al (2009) Multi-residue screening of veterinary drugs in egg, fish and meat using high-resolution liquid chromatography accurate mass time-of-flight mass spectrometry. J Chromatogr A 1216:8206-16. doi:10.1016/j.chroma.2009.04.027

Reddersen K, Heberer T (2003) Short communication. Formation of an artifact of diclofenac during acidic extraction of environmental water samples. J Chromatogr A 1011:221-226

Robert C, Gillard N, Brasseur P-Y et al (2013) Rapid multi-residue and multi-class qualitative screening for veterinary drugs in foods of animal origin by UHPLC-MS/MS. Food Addit Contam Part A: Chem Anal Control Expo Risk Assess 30:443-57. doi:10.1080/ 19440049.2012.751632

Tölgyesi A, Sharma VK, Fekete S et al (2012) Simultaneous determination of eight corticosteroids in bovine tissues using liquid 
chromatography-tandem mass spectrometry. J Chromatogr B Analyt Technol Biomed Life Sci 906:75-84. doi:10.1016/j.jchromb.2012. 08.033

Van den Hauwe O, Dumoulin F, Antignac J et al (2002) Liquid chromatographic-mass spectrometric analysis of 11 glucocorticoid residues and an optimization of enzymatic hydrolysis conditions in bovine liver. Anal Chim Acta 473:127-134. doi:10.1016/S0003-2670(02) 00754-7
Vree TB, Verwey-van Wissen CP, Lagerwerf AJ et al (1999) Isolation and identification of the C6-hydroxy and C20-hydroxy metabolites and glucuronide conjugate of methylprednisolone by preparative highperformance liquid chromatography from urine of patients receiving high-dose pulse therapy. J Chromatogr B Biomed Sci Appl 726: $157-68$

Wang J, MacNeil JD, Kay JF (2011) Chemical analysis of antibiotic residues in food. Wiley, Hoboken, New Jersey 